\title{
Microwave-Assisted Synthesis of Poly(2-hydroxyethyl methacrylate) (HEMA)/Silica Hybrid Using in situ Polymerization Method
}

\author{
By Yuichi KAJIWARA, ${ }^{1,2}$ Atsushi NAGAI, ${ }^{1}$ and Yoshiki CHUJO $^{1, *}$
}

\begin{abstract}
A facile and fast synthesis of poly(2-hydroxyethyl methacrylate) (PHEMA)/silica hybrid was achieved using in situ polymerization method under microwave irradiation, in which the polymerization of 2-hydroxyethyl methacrylate (HEMA) was carried out together with the sol-gel reaction of methyltrimethoxysilane (MeTMOS). The preparation rate of the hybrid under microwave irradiation was accelerated rapidly relative to that under conventional heating due to the activation of hydroxyl groups of HEMA and silanol groups of alkoxysilanes by microwave irradiation. When acetic acid was used as a catalyst for the sol-gel reaction of MeTMOS, the transparency of the hybrid was improved. The transparency, homogeneity, and formability of the hybrid prepared under microwave irradiation were better than those prepared under conventional heating. In addition, it was found that the degree of polymerization of HEMA under microwave irradiation is higher than that under conventional heating by using FT-IR spectroscopy due to the activation of the polymerization of HEMA. Thermal properties of the hybrids prepared under microwave irradiation were almost identical to those under conventional heating. KEY WORDS: Microwave / Organic-Inorganic Hybrid / In Situ Polymerization Method /
\end{abstract}

The methodology of microwave irradiation has attracted growing attention in the field of organic chemistry as an alternative heating method. ${ }^{1,2}$ The main advantages of the microwave-assisted chemistry are faster reaction rate, higher yields, and a reduction of side reactions compared with syntheses performed under conventional heating. Microwave irradiation can heat up the polar materials rapidly by a dielectric heating mechanism. Microwave-assisted polymer syntheses have also been widely studied. ${ }^{3,4}$ For example, Gourdenne et al. reported that the bulk polymerization of 2hydroxyethyl methacrylate (HEMA) could be activated by microwave irradiation without an initiator. ${ }^{5}$

Organic-inorganic polymer hybrids have been widely studied because of their high performance and unique properties. ${ }^{6}$ Generally, the sol-gel reaction of alkoxysilane in the presence of various polymers, such as poly $(N$-vinylpyrrolidone), ${ }^{7}$ poly(2-methyl-2-oxazoline) ${ }^{8}$ polystyrene, ${ }^{9}$ and so on, is used to prepare hybrid materials via specific interactions such as hydrogen bonding, covalent bonding, $\pi-\pi$ interaction, and so on. The in situ polymerization method, which is the simultaneous polymerization of organic monomers during the formation of silica gel from metal alkoxides, is very useful and convenient technique for the preparation of hybrid materials to overcome the phase separation between organic and inorganic phases. Novak et al. reported the preparation of polyacrylate/ silica hybrids without significant volume shrinkage using in situ polymerization method, in which the removal of organic solvents such as methanol and water is not needed. ${ }^{10,11}$ Moreover, the hybrids from the polymers such as polystyrene which have the poor affinity with a silica gel can be prepared by the in situ polymerization methods. ${ }^{12}$ Poly(2-hydroxyethyl methacrylate) (PHEMA), which is a biocompatible polymer and widely employed for biomedical applications, and silica hybrids were also prepared by the in situ polymerization method. ${ }^{13-18}$ However, in many cases, more than $24 \mathrm{~h}$ are required to obtain the hybrids under conventional heating.

Generally, when the sol-gel reaction is carried out under mild conditions, long reaction times are needed to achieve a high cross-linking degree. Recently, to overcome this drawback, microwave irradiation has been applied to the preparation of some polymer hybrids because the polar silanol groups generated by hydrolysis of alkoxysilane are activated. ${ }^{19-21} \mathrm{By}$ microwave irradiation, the shortening of the preparation time of hybrid materials was achieved. However, there are few reports applying microwave irradiation to the preparation of the polymer/silica hybrid using in situ polymerization method. ${ }^{22}$ Further, to the best of our knowledge, microwave-assisted in situ polymerization method involving the sol-gel reaction of alkoxysilane has not been reported so far.

In the present paper, we propose the facile preparation of polymer/silica hybrids by in situ polymerization method under microwave irradiation, where 2-hydroxyethyl methacrylate (HEMA) and methyltrimethoxysilane (MeTMOS) were used as an organic monomer and a silica gel precursor, respectively. It is expected that both the polymerization of HEMA and the sol-gel reaction of MeTMOS can be accelerated under microwave irradiation as compared to conventional heating. In addition, the transparency, chemical structure, and thermal properties of the PHEMA/silica hybrids prepared under both methods were evaluated by scanning electron microscopy (SEM), Fourier transform infrared (FT-IR) spectroscopy, differential scanning calorimetry (DSC), and thermogravimetric analysis (TGA).

\footnotetext{
${ }^{1}$ Department of Polymer Chemistry, Graduate School of Engineering, Kyoto University, Katsura, Nishikyo-ku, Kyoto 615-8510, Japan

${ }^{2}$ Matsumoto Yushi-Seiyaku Co., Ltd., 2-1-3, Shibukawa-cho, Yao-City, Osaka 581-0075, Japan

*To whom correspondence should be addressed (Tel: +81-75-383-2604, Fax: +81-75-383-2605, E-mail: chujo@chujo.synchem.kyoto-u.ac.jp).
} 
Table I. Preparation of PHEMA/silica hybrids under microwave irradiation and conventional heating ${ }^{\mathrm{a}}$

\begin{tabular}{cccccc}
\hline run & $\begin{array}{c}\text { HEMA } \\
(\mathrm{g})\end{array}$ & $\begin{array}{c}\text { MeTMOS } \\
(\mathrm{g})\end{array}$ & catalyst & \multicolumn{2}{c}{ appearance } \\
\cline { 3 - 5 } & 1.0 & 2.0 & $\mathrm{HCl}$ & $\mathrm{MW}^{\mathrm{c}}$ & $\mathrm{CH}^{\mathrm{d}}$ \\
2 & 1.0 & 2.0 & $\mathrm{CH}_{3} \mathrm{COOH}$ & translucent & turbid gel \\
3 & 0.50 & 2.0 & $\mathrm{CH}_{3} \mathrm{COOH}$ & transparent & soft gel \\
4 & 0.20 & 2.0 & $\mathrm{CH}_{3} \mathrm{COOH}$ & transparent & transparent/crack \\
5 & 1.0 & 1.0 & $\mathrm{CH}_{3} \mathrm{COOH}$ & transparent & surface shrinkage \\
6 & 1.0 & 0.50 & $\mathrm{CH}_{3} \mathrm{COOH}$ & transparent & surface shrinkage \\
\hline
\end{tabular}

a Solvent: $\mathrm{CH}_{3} \mathrm{OH} 3.0 \mathrm{~mL}$. ${ }^{\mathrm{b}} \mathrm{HCl}$ : $0.1 \mathrm{~N}$ hydrochloric acid $1.0 \mathrm{~mL}$. $\mathrm{CH}_{3} \mathrm{COOH}: 0.6 \%$ acetic acid aqueous solution $1.0 \mathrm{~mL}$. ${ }^{\mathrm{c}}$ Reactions under microwave irradiation (MW) were carried out with three steps; $30 \mathrm{~W} 40 \mathrm{~min}, 100 \mathrm{~W} 10 \mathrm{~min}$, and $300 \mathrm{~W} 5 \mathrm{~min}$. ${ }^{\mathrm{d}}$ Reactions under conventional heating $(\mathrm{CH})$ were carried out in an oven at $60^{\circ} \mathrm{C}$ for $24 \mathrm{~h}$. ${ }^{\mathrm{e}}$ Reaction was carried out with three steps; $30 \mathrm{~W} 40 \mathrm{~min}, 100 \mathrm{~W} 10 \mathrm{~min}$, and $500 \mathrm{~W} 5 \mathrm{~min}$

\section{EXPERIMENTAL}

\section{Materials}

2-Hydroxyethyl methacrylate (HEMA) was distilled under reduced pressure. 2,2'-Azobis(isobutyronitrile) (AIBN) was recrystallized from methanol. Methyltrimethoxysilane (MeTMOS), methanol (analytical grade), acetic acid, $0.1 \mathrm{~N}$ hydrochloric acid aqueous solution, and 2-hydroxyethyl acetate were used as received without further purification. Acetic acid aqueous solution $(0.6 \%)$ was prepared by dissolving $0.6 \mathrm{~g}$ of acetic acid in $100 \mathrm{~g}$ of distilled water.

\section{Preparation and Characterization of HEMA/Silica Hybrid}

HEMA, AIBN, and MeTMOS were dissolved in methanol followed by an addition of acid under vigorous stirring. After stirring for $3 \mathrm{~h}, 1.5 \mathrm{~g}$ of the solution was poured into a $5 \mathrm{~mL}$ polypropylene beaker. The solution was put into a microwave reactor (Milestone General MicroSYNTH). $2.45 \mathrm{GHz}$ microwave was irradiated under nitrogen atmosphere for the prescribed conditions. For the conventional heating, the solution was put into a $60^{\circ} \mathrm{C}$ oven under argon atmosphere for $24 \mathrm{~h}$.

\section{Solvent Extraction}

The powdered hybrids were put in cellulose timbers $(20 \mathrm{~mm} \times 80 \mathrm{~mm})$ and extracted with methanol. After extraction for $24 \mathrm{~h}$, the samples were dried in a vacuum oven at $60^{\circ} \mathrm{C}$.

\section{Measurements}

UV-vis spectra were obtained on a SHIMADZU UV-visNIR Spectrometer UV-3600. Scanning electron microscopy (SEM) measurements were conducted using a JEOL JSM-5600 system. Fourier transform infrared (FT-IR) spectra were recorded on a Parkin Elmer 1600 infrared spectrometer. Differential scanning calorimetry (DSC) thermograms were obtained with a DSC 200, SEIKO Instruments, Inc. All samples were heated from room temperature to $200^{\circ} \mathrm{C}$ and cooled to $40{ }^{\circ} \mathrm{C}$, and then they were re-heated to $200^{\circ} \mathrm{C}$ under nitrogen atmosphere. The heating rate was $10^{\circ} \mathrm{C} / \mathrm{min}$, and the cooling rate was $50{ }^{\circ} \mathrm{C} / \mathrm{min}$. The second scan of heating was recorded. Thermogravimetric analysis (TGA) was performed on a SEIKO TG/DTA 6200 with a heating rate of $10^{\circ} \mathrm{C} / \mathrm{min}$ in air.

\section{RESULTS AND DISCUSSION}

2-Hydroxyethyl methacrylate (HEMA) as a hydrophilic monomer possesses a hydroxyl group which can interact with silanol group generated by hydrolysis of alkoxysilane. Therefore it allows the construction of homogeneous disperse system during the sol-gel reaction of alkoxysilane. Further, HEMA can be activated by microwave irradiation due to polar groups such as ester and hydroxyl groups, and is appropriate for the use of open-vessel reaction due to high boiling point (about $250^{\circ} \mathrm{C}$ ).

The polymerization of 2-hydroxyethyl methacrylate (HEMA) was carried out together with the sol-gel reaction of methyltrimethoxysilane (MeTMOS) under microwave irradiation or conventional heating in the presence of $2,2^{\prime}$-azobis(isobutyronitrile) (AIBN) as a radical initiator and $0.1 N$-hydrochloric acid as a catalyst for sol-gel reaction. Table I summarizes the feed ratio of reagents and visible appearance. In the feed ratio at [HEMA] $/[\mathrm{MeTMOS}]=1 / 2$ and the molar ratio at [AIBN]/ $[$ HEMA $]=0.001$, conventional heating in an oven at $60^{\circ} \mathrm{C}$ for $24 \mathrm{~h}$ led to the formation of turbid gel (Figure $1 \mathrm{~b}$ ). In contrast, translucent plate of the hybrid was obtained under three stepsmicrowave irradiation $(30 \mathrm{~W}$ for $40 \mathrm{~min}, 100 \mathrm{~W}$ for $10 \mathrm{~min}$ and $500 \mathrm{~W}$ for $5 \mathrm{~min}$ ) for only $55 \mathrm{~min}$ (Figure $1 \mathrm{a}$ ).

The SEM images of surface morphology of these hybrids are shown in Figure 1c and 1d. A few heterogeneous parts exist in the hybrid prepared under microwave irradiation. In contrast, a large amount of particles were observed in the materials prepared under conventional heating, resulting in the formation of turbid gel. This different morphology is attributed to the activation of hydroxyl groups in HEMA and silanol groups generated by hydrolysis of MeTMOS under microwave irradiation or conventional heating; i.e., the radical polymerization of HEMA and the sol-gel reaction of MeTMOS with hydrochloric acid are accelerated rapidly and simultaneously before the formation of phase separation under microwave irradiation, and the condensation of hydroxyl groups of HEMA with the silanol groups are significantly enhanced by microwave irradiation, leading to the nearly transparent hybrid. On the other hand, the large silica particles were formed because the hydrochloric acid-catalyzed sol-gel reaction of MeTMOS proceeded before the polymerization of HEMA under conventional heating, resulting in phase separation of the hybrids. 
(a)

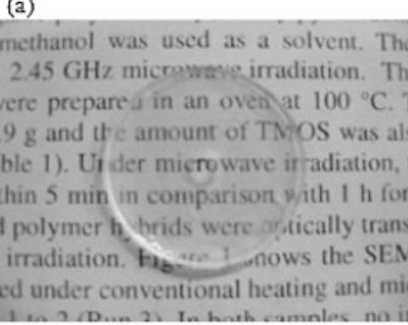

(c)

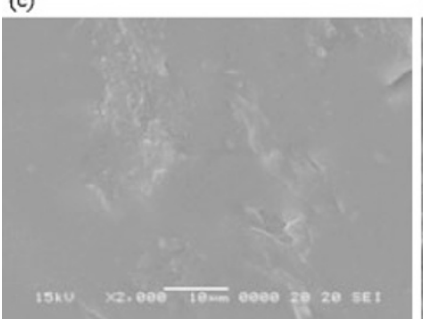

(b)

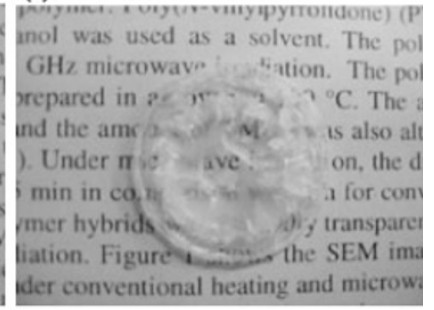

(d)

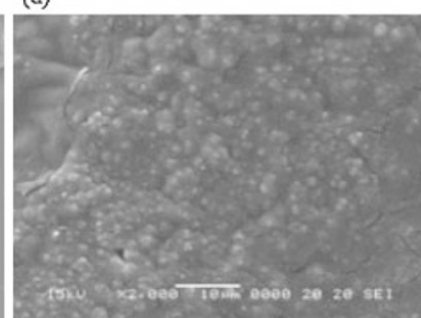

Figure 1. Pictures (a, b) and SEM images (c, d) of PHEMA/silica hybrids ([HEMA]/[MeTMOS] = 1/2) using hydrochloric acid as a catalyst of sol-gel reaction of MeTMOS prepared under microwave irradiation $(a, c)$, and conventional heating $(b, d)$.

(a)

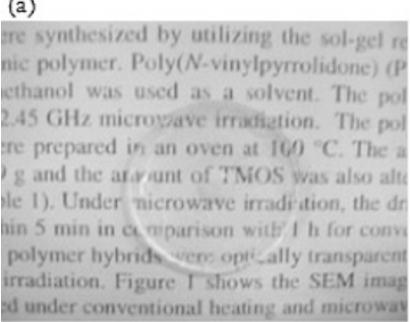

(c)

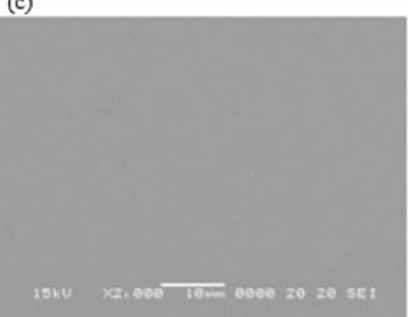

(b)

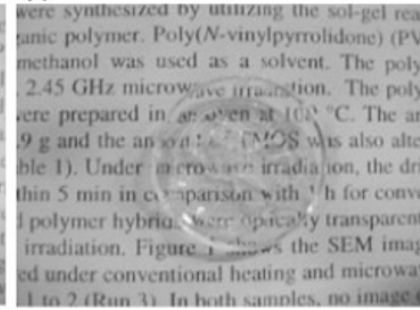

(d)

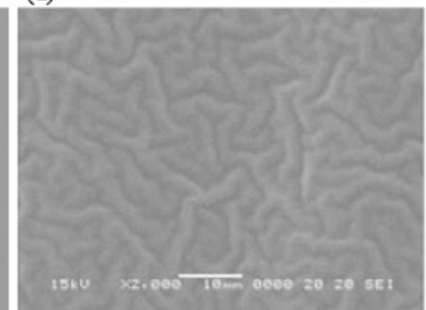

Figure 2. Pictures (a, b) and SEM images (c, d) of PHEMA/silica hybrids ([HEMA]/[MeTMOS] = 1/2) using acetic acid as a catalyst of solgel reaction of MeTMOS prepared under microwave irradiation (a, $c)$, and conventional heating (b, d).

Next, we used acetic acid as a catalyst of sol-gel reaction of MeTMOS. As shown in Figure $2 a$ and $2 b$, transparent hard hybrid gel was obtained under three step-microwave irradiation ( $30 \mathrm{~W}$ for $40 \mathrm{~min}, 100 \mathrm{~W}$ for $10 \mathrm{~min}$ and $300 \mathrm{~W}$ for $5 \mathrm{~min}$ ), whereas soft and gummy hybrids with some cracks were obtained under conventional heating. The SEM images of the hybrids are shown in Figure $2 \mathrm{c}$ and $2 \mathrm{~d}$. No silica particle or heterogeneous part was observed in the hybrid prepared under microwave irradiation. In contrast, phase separation was observed in the materials prepared under conventional heating. Since the sol-gel reaction of MeTMOS catalyzed by acetic acid is slow as compared to using hydrochloric acid, the formation of large silica particles could be suppressed. Under microwave

Table II. Condensation degree of 2-hydroxyethyl acetate with silanol groups derived from MeTMOS under microwave irradiation and conventional heating ${ }^{\mathrm{a}}$

\begin{tabular}{ccc}
\hline heating method & $\begin{array}{c}\text { organic content }^{\mathrm{d}} \\
(\%)\end{array}$ & $\begin{array}{c}\text { condensation degree } \\
(\%)\end{array}$ \\
\hline microwave $^{\mathrm{b}}$ & 35.4 & 25 \\
conventional $^{\mathrm{c}}$ & 26.0 & 4.6 \\
\hline
\end{tabular}

a2-Hydroxyethyl acetate $0.80 \mathrm{~g}$, MeTMOS $2.0 \mathrm{~g}, \mathrm{CH}_{3} \mathrm{OH} 3.0 \mathrm{~mL}, 0.6 \%$ acetic acid aqueous solution $1.0 \mathrm{~mL}$. b Reaction condition: $30 \mathrm{~W} 40 \mathrm{~min}$, $100 \mathrm{~W} 10 \mathrm{~min}$, and $300 \mathrm{~W} 5 \mathrm{~min}$. ' Reaction condition: $60^{\circ} \mathrm{C}, 24 \mathrm{~h}$.

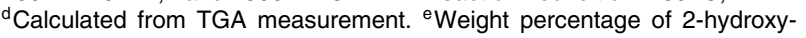
ethyl acetate which condensed with silanol groups.

irradiation, the sol-gel reaction of MeTMOS would be rapid enough to construct a hard silica gel, and the condensation of hydroxyl groups with the silanol groups would proceed efficiently through the formation of the transparent and hard hybrid gel. In contrast, under conventional heating, slow solgel reaction of MeTMOS leads to the incomplete formation of the hybrid gel or phase separation between PHEMA and silica.

To investigate whether the condensation degree between hydroxyl groups and the silanol groups was enhanced, sol-gel reaction of MeTMOS was carried out in the presence of 2hydroxyethyl acetate instead of HEMA monomer under microwave irradiation and conventional heating. The obtained silica gels were extracted by soxhlet extraction with methanol for $24 \mathrm{~h}$ which removed unreacted 2-hydroxyethyl acetate, and organic content of the silica gels after extraction was measured by thermogravimetric analysis (TGA). Here, the weight percentage of 2-hydroxyethyl acetate condensed with silanol groups is regarded as the condensation degree, which can be calculated by the organic content of the silica gels. ${ }^{13}$ As shown in Table II, it was found that the condensation degree under microwave irradiation was higher than that under conventional heating. This result suggests that the condensation reaction between hydroxyl groups of HEMA monomer and the silanol groups is also enhanced by microwave irradiation.

The transparency of the hybrids prepared under microwave irradiation was measured by means of UV-vis spectroscopy (Figure 3). Transmittance of the hybrid prepared with acetic acid was $91 \%$ at $700 \mathrm{~nm}$, indicating higher transparency than that of the hybrid prepared using hydrochloric acid.

The polymerization of HEMA was monitored by FT-IR spectroscopy. Figure 4 shows the spectra of HEMA monomer and the hybrids prepared under microwave irradiation and conventional heating. The characteristic absorption bands at $1724 \mathrm{~cm}^{-1}$ and $1638 \mathrm{~cm}^{-1}$ can be assigned to the stretching vibrations of carbonyl bonds and carbon-carbon double bonds, respectively, in the HEMA monomer. ${ }^{13}$ The intensity of the $\mathrm{C}=\mathrm{C}$ absorption band at $1638 \mathrm{~cm}^{-1}$ decreased significantly, supporting the occurrence of the vinyl polymerization of HEMA in the silica gel matrix. Since the carbonyl groups were not involved in the radical polymerization, the relative intensity of the $\mathrm{C}=\mathrm{C}$ absorption can be used to evaluate the degree of the vinyl polymerization of HEMA. As shown in Figure 4, the relative intensity of the hybrid prepared under microwave irradiation was smaller than that prepared under conventional heating, indicating that the conversion of HEMA monomer 


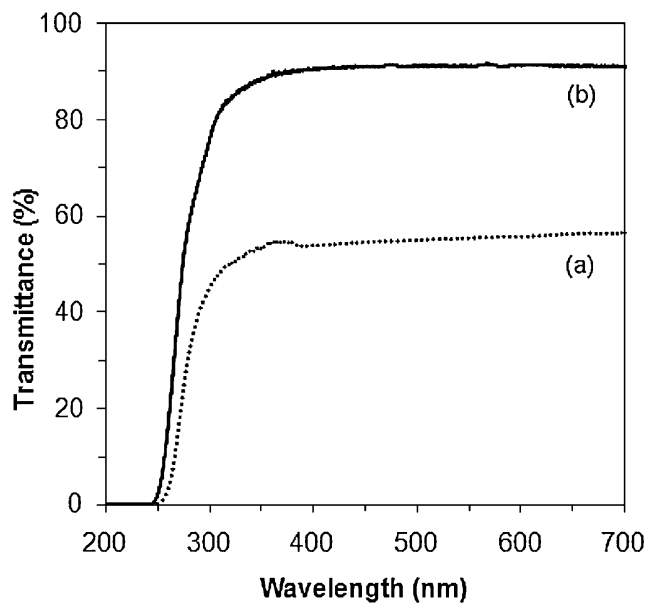

Figure 3. UV-vis spectra of PHEMA/silica hybrids ([HEMA]/[MeTMOS] = 1/2) prepared under microwave irradiation using hydrochloric acid (a) and acetic acid (b) as a catalyst of sol-gel reaction of methyltrimethoxysilane.

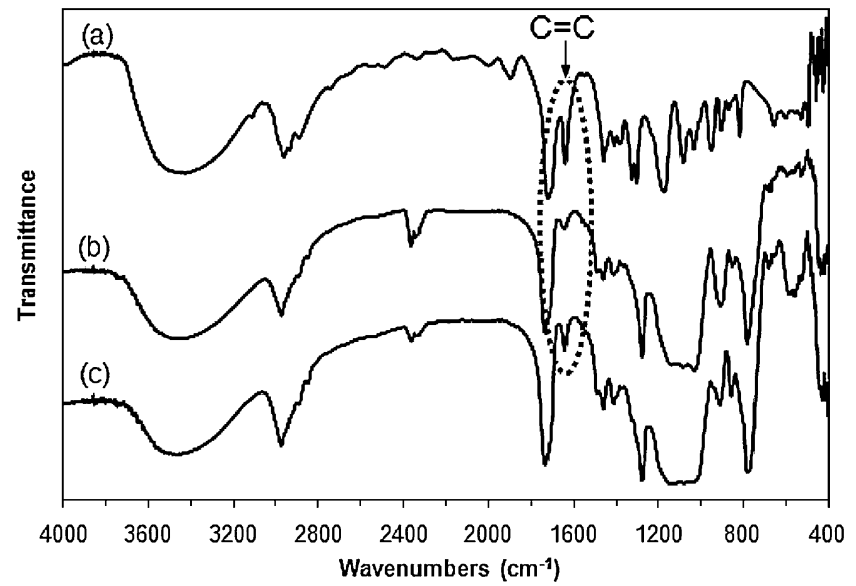

Figure 4. FT-IR spectra of HEMA monomer (a), PHEMA/silica hybrids prepared under microwave irradiation (run 2 in Table I) (b), and conventional heating (run 2 in Table I) (c). The feed ratio of $[\mathrm{HEMA}] /[\mathrm{MeTMOS}]=1 / 2$, and acetic acid was used as a catalyst.

under microwave irradiation is higher as compared to conventional heating. The difference between both methods would affect the hardness of the hybrid.

Further, PHEMA/silica hybrids with different silica contents were prepared under both methods. The feed ratios of [HEMA]/[MeTMOS] are summarized in Table I (runs 2-6). No cracks were observed in all the hybrids prepared under microwave irradiation. In contrast, the hybrids prepared under conventional heating exist cracks or gummy except for the hybrid of $[\mathrm{HEMA}] /[\mathrm{MeTMOS}]=1 / 10$ (run 4). These results indicate that microwave irradiation provides homogeneous and transparent PHEMA/silica hybrids in a wide composition range.

The thermal properties of the hybrids prepared under both methods were examined by DSC and TGA measurements. Figure 5 shows the DSC curves of PHEMA and the hybrids of $[$ HEMA $] /[$ MeTMOS $]=1 / 2$ prepared under both methods

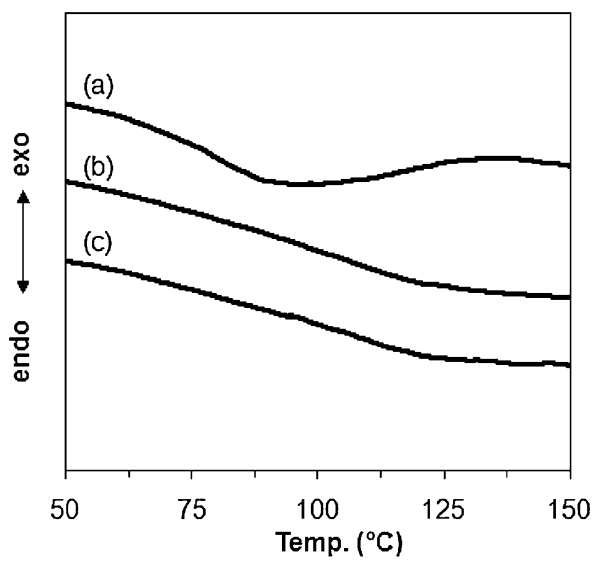

Figure 5. DSC curves of PHEMA (a), PHEMA/silica hybrid prepared under microwave irradiation (b), and prepared under conventional heating (c). The feed ratio of $[\mathrm{HEMA}] /[\mathrm{MeTMOS}]=1 / 2$.

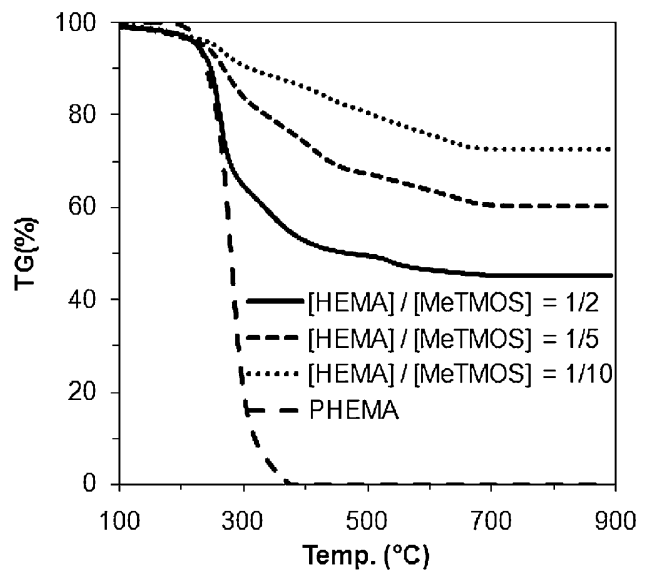

Figure 6. TGA curves of PHEMA and PHEMA/silica hybrids with different silica contents prepared under microwave irradiation.

(Table I, run 2). The glass transition temperature $\left(T_{\mathrm{g}}\right)$ of PHEMA was $85^{\circ} \mathrm{C}$, whereas the hybrid shows no significant peak of $T_{\mathrm{g}}$. The disappearance of $T_{\mathrm{g}}$ implies that the motion of the PHEMA chains was seriously restricted by the silica matrix. TGA curves of the hybrids prepared under microwave irradiation and conventional heating are illustrated in Figures 6 and 7 , respectively. The thermal decomposition temperature $\left(T_{10}\right)$ shifted to higher value with increasing of the silica content, e.g., $T_{10}$ of the hybrid of [HEMA]/[MeTMOS] $=$ $1 / 10$ prepared under microwave irradiation was shifted from $241{ }^{\circ} \mathrm{C}$ to $313^{\circ} \mathrm{C}$. The thermal properties of the hybrids prepared under microwave irradiation were almost identical to those prepared under conventional heating.

\section{CONCLUSION}

In the present paper, we demonstrated the facile preparation of PHEMA/silica hybrid using in situ polymerization method under microwave irradiation. The radical polymerization of HEMA was carried out together with the sol-gel reaction of MeTMOS. By microwave irradiation, PHEMA/silica hybrids 


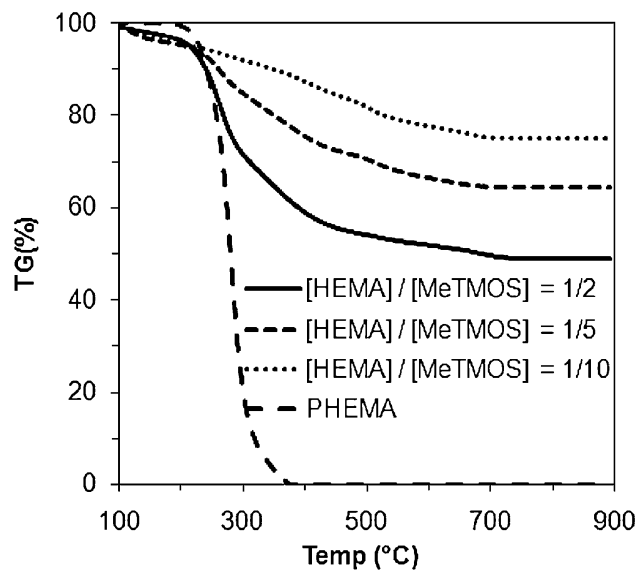

Figure 7. TGA curves of PHEMA and PHEMA/silica hybrids with different silica contents prepared under conventional heating.

with high transparency and without crack formation were obtained in a short time as compared to the conventional heating. It was found that irradiation of microwave accelerated the preparation rate of PHEMA/silica hybrid. When acetic acid was employed as a catalyst of the sol-gel reaction of MeTMOS, the transparency of the hybrids was higher than that prepared using hydrochloric acid. The homogeneity of the hybrids was improved by microwave irradiation probably due to the rapid reaction and enhancement of condensation degree between hydroxyl groups of HEMA and silanol groups as compared to conventional heating. No phase separation was observed in the SEM images of the hybrid prepared under microwave irradiation. FT-IR spectra showed that the polymerization of HEMA proceeded rapidly in the preparation of hybrids under microwave irradiation. The thermal properties of the hybrids prepared under microwave irradiation were almost identical to those prepared under conventional heating.
Received: June 27, 2009

Accepted: August 15, 2009

Published: October 2, 2009

\section{REFERENCES}

1. A. de la Hoz, Á. D.-Ortiz, and A. Moreno, Chem. Soc. Rev., 34, 164 (2005).

2. C. O. Kappe, Angew. Chem., Int. Ed., 43, 6250 (2004).

3. S. Sinnwell and H. Ritter, Aust. J. Chem., 60, 729 (2007).

4. R. Hoogenboom and U. S. Schubert, Macromol. Rapid Commun., 28, 368 (2007).

5. M. Teffal and A. Gourdenne, Eur. Polym. J., 19, 543 (1983).

6. T. Ogoshi and Y. Chujo, Compos. Interfaces, 11, 539 (2005).

7. M. Toki, T. Y. Chow, T. Ohnaka, H. Samura, and T. Saegusa, Polym. Bull., 29, 653 (1992).

8. Y. Chujo, E. Ihara, S. Kure, and T. Saegusa, Macromolecules, 26, 5681 (1993).

9. R. Tamaki, K. Samura, and Y. Chujo, Chem. Commun., 1131 (1998).

10. M. W. Ellsworth and B. M. Novak, J. Am. Chem. Soc., 113, 2756 (1991).

11. B. M. Novak and C. Davies, Macromolecules, 24, 5481 (1991).

12. R. Tamaki, K. Naka, and Y. Chujo, Polym. Bull., 39, 303 (1997).

13. Y. Wei, D. Jin, C. Yang, and G. Wei, J. Sol-Gel Sci. Technol., 7, 191 (1996).

14. Z. H. Huang and K. Y. Qiu, Polymer, 38, 521 (1997).

15. Y. Wei, D. Jin, C. Yang, M. C. Kels, and K. Y. Qiu, Mater. Sci. Eng., C, 6, 91 (1998).

16. P. Hajji, L. David, J. F. Gerard, J. P. Pascault, and G. Vigier, J. Polym. Sci., Part B: Polym. Phys., 37, 3172 (1999).

17. S. Li, A. Shah, A. J. Hsieh, R. Haghighat, S. S. Praveen, I. Mukherjee, E. Wei, Z. Zhang, and Y. Wei, Polymer, 48, 3982 (2007).

18. A. Costantini, G. Luiciani, B. Silvestri, F. Tescione, and F. Branda, $J$. Biomed. Mater. Res., Part B, 86B, 98 (2008).

19. K. Adachi, T. Iwamura, and Y. Chujo, Polym. Bull., 55, 309 (2005).

20. M. Geppi, G. Mollica, and S. Borsacchi, J. Mater. Res., 22, 3516 (2007).

21. K. Kuraoka and A. Hashimoto, J. Ceram. Soc. Jpn., 116, 832 (2008).

22. P. Liu and Z. Su, Mater. Chem. Phys., 94, 412 (2005). 